\title{
The Paleoenvironmental Database of China (PDC)
}

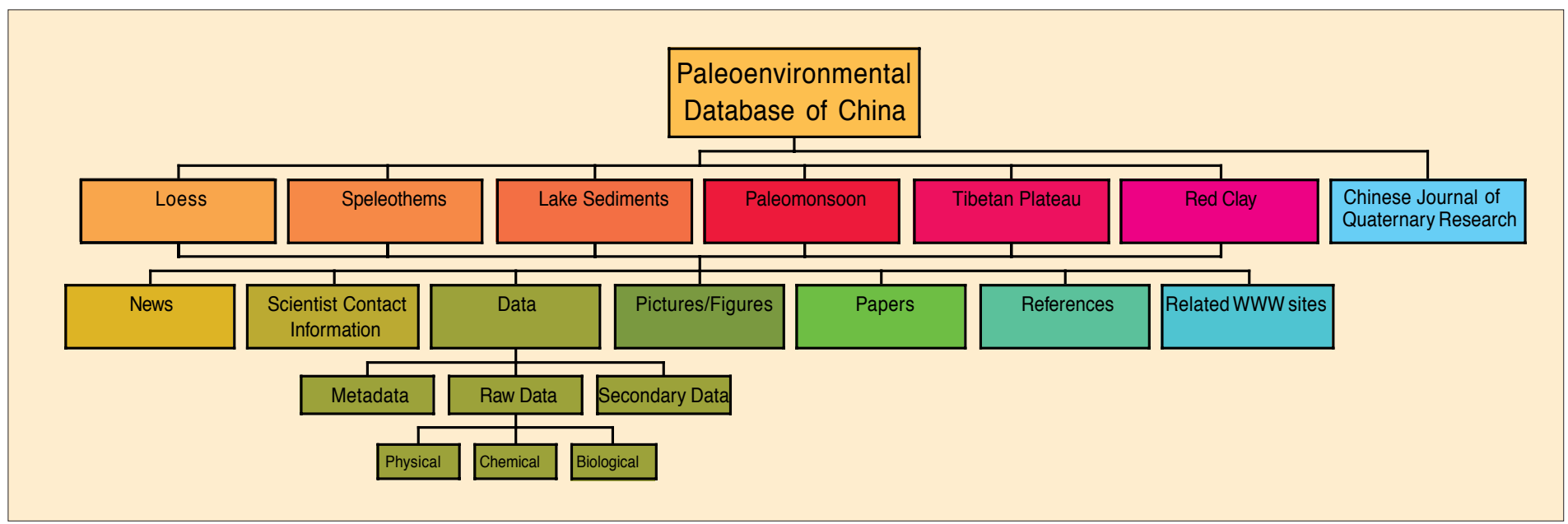

Schematic outline of the structure of the Paleoenvironmental Database of China (PDC)

The Paleoenvironmental Database of China (PDC) has been established at the Institute of Geology, Chinese Academy of Sciences. The database is financially supported by the National Natural Scientific Foundation of China (NNSFC) and the Chinese Academy of Sciences (CAS). Its scientific objectives are to create a management system for paleoenvironmental and modern climatic data, to develop analytical methods for quantitative and qualitative study of the dynamical and statistical characteristics of paleoclimate, and to make these data readily available to the international scientific research community.

The database consists of three parts:

\section{The Modern Environmental Database}

contains monthly mean temperature and precipitation throughout China as well as other modern climatic data. The database also provides some secondary data such as the efficient index of temperature or precipitation, the continental degree of temperature, the possible evaporation and the humidity index.

\section{The Paleoenvironmental Database}

mainly manages climatic and environmental information derived from loess, lake and stalagmite archives, as well as information on past sea level, desert extent, and paleo-vegetation. The information includes original data, secondary data, images and figures. Physical, chemical and geological properties of loess and speleothems currently make up the bulk of the data in the database. In order to provide boundary conditions for general circulation model
(GCM) simulations, paleoenvironmental reconstructions of China for several time slices are also contained in the database. The paleodata of the PDC come from two important sources: Chinese research programs and other published papers.

\section{The Analysis Software}

consists of numerous programs that can be used to quantitatively analyze various characteristics of environmental change. The mathematical methods fall into the following categories: (1) time scale transfer (from depth to time) (2) power spectrum analysis (including moving power analysis) (3) transfer functions to convert from proxy indices to climatic parameters (4) response surface analysis (trend surface analysis) (5) fractal dimension analysis (6) time series analysis (7) the BP neural network for predicting future climatic change (8) laminae analysis software for extracting information of microlayers in speleothems.

\section{Website Under Construction}

Construction of an internet accessible version of PDC began shortly after the PAGES second workshop on global paleoenvironmental data, held in February, 1998. The structure of the database required minor modification based on the requirements of the internet. At present, it contains sections on loess, speleothems, tree rings, lake sediments (especially maar lakes), paleomonsoons, red clay and the Tibetan plateau, as well as the Chinese Journal of Quaternary Research. Within each of these individual topics can be found research news, data, pictures and figures, contact information for relevant Chinese scientists, papers published by Chinese scientists, a list of references and relevant internet links. On the homepages of the Chinese Journal Quaternary Research, the title and abstract of every paper are also provided in English. The database on the internet is displayed in two languages, Chinese and English. All data in the database are coded so as to be compatible with formats used in the World Data Center (WDC-A).

Although the storage of data and meta-data as described above has begun, and new information is being archived continuously, the database can not yet be publicly accessed because of some remaining difficulties which include limited financial support, assignment of an official domain name for the WWW-site, an incomplete meta-data section acknowledging the data producers and other technical problems.

As we are making great efforts to solve these problems, internet access to the PDC will be available in the near future. In the coming years, we expect more data will be put into the internet database of PDC together with analysis software. Users will be able to retrieve both the information they require as well as analysis methods to study these paleodata.

\section{Qin Xiaoguang}

Institute of Geology, Chinese Academy of Sciences, Beijing, China

qinxg@public.east.cn.net or

pdc-lsp@igcas.igcas.ac.cn 